\title{
Psychological Effect of COVID-19 among Nursing Students
}

\author{
Niran Shrestha $^{1}$, Nirmala Ghimire ${ }^{2}$, Roshani Khatry ${ }^{3}$, Ratna Maharjan ${ }^{4}$ \\ ${ }^{1,2,3,4}$ Assistant Professor, Patan Academy of Health Sciences School of Nursing and Midwifery (PAHS), \\ School of Nursing and Midwifery, Sanepa, Lalitpur, Nepal \\ Corresponding Author: Niran Shrestha
}

\begin{abstract}
Objective: Novel Corona Virus Disease (COVID-19) has not only brought the risk of morbidity and mortality but also psychological burden on individuals. The objective of the study was to assess psychological effect of COVID- 19 among nursing students of Patan Academy of Health Sciences School of Nursing and midwifery, Lalitpur, Nepal.

Method: A cross sectional analytical study was conducted in July 2020 among 382 nursing students. Stress was assessed by Perceived Stress Scale (PSS) 10 item scale, Anxiety level was assessed using Generalized Anxiety Disorder 7-Item Scale and depression with Patient Health Questionnaire (PHQ) 9 item scale. The total enumerative sampling technique was used for sample selection and data was collected by an online survey. Descriptive and inferential statistics were used to analyze data.

Result: The findings of the study revealed that that 278 (72.8\%) nursing students had moderate level and $11(2.9 \%)$ had high perceived stress, $202(52.9 \%)$ had mild anxiety and only $8(2.1 \%)$ had severe anxiety. Regarding depression, 220 (57.6\%) did not have depressive symptoms and only $4(1 \%)$ had severe depression. Significant mean difference in stress, anxiety and depression between PCL, BSc and BNS were found with $\mathrm{p}$ value $<0.05$ which indicated that PCL students were more likely to be stressed, anxious and depressed than B.Sc. and BNS due to COVID 19.

Conclusion: The survey revealed that the majority of nursing students had moderate level of stress, mild anxiety and no depressive symptoms during COVID 19. In order to improve the psychological status of students, the government and organizations should collaborate with educational institutions to ensure psychological support to the students.
\end{abstract}

Keywords: Anxiety, COVID 19, depression, nursing students, psychological effect, stress, students.

\section{INTRODUCTION}

COVID-19, the infection caused by a novel corona virus detected in Wuhan in December 2019, is declared as a global pandemic by World Health Organization (WHO), has raised concerns of widespread panic and anxiety among [1]. Similarly, university students are vulnerable to the mental health sequelae of the COVID-19related confinement. ${ }^{[2-4]}$

In University of Spain, moderate to extremely severe scores of stress, anxiety and depression were reported by $28.14 \%$, $21.34 \%$, and $34.19 \%$ respondents, respectively. ${ }^{[3]}$ Likewise, in Bangladesh, $58.6 \%$ of college students experienced stress, $63.6 \%$ anxiety, and $62.9 \%$ depression. [2] In Chitwan, Nepal, prevalence of mild anxiety was $45.4 \%$ and moderate stress was $84.1 \%$ among nursing students. ${ }^{[5]}$

In Nepal, 9561 cases of confirmed COVID-19 with 23 deaths were recorded by 23 June $2020^{[1]}$ and it was escalating day by day. Due to this students were confined at home and were taking online classes, which in turn have brought forward the uncertainty for leading a normal campus life. This may 
affect their psychological well being. Hence, the aim of the study was to identify the psychological effects of COVID-19 among nursing students

\section{MATERIALS AND METHODS}

A cross-sectional analytical study was conducted among undergraduate and post graduate nursing students of Patan Academy of Health Sciences, School of Nursing and Midwifery. Total nursing students were 428 from Proficiency Certificate level (PCL), Bachelor of Science in Nursing (B. Sc.), Bachelor of Nursing Science (BNS) and master level. Among them, 9 were excluded from study due to psychiatric illness and under medication and 37 did not respond. So, total 382 students were enrolled in the study and response rate was $89 \%$. Data was collected by an online survey via Google form from 2020/8/5 to 2020/12 with a structured questionnaire in English.

Ethical approval was taken from the Institutional Review Committee (IRC) of the Patan Academy of Health Science (PAHS) and formal administrative permission was obtained from the dean of school of nursing and midwifery. Email address of students was obtained from administration office. Introduction of study with objectives along with instructions to complete the questionnaire was provided in the information sheet. The participation was voluntary and only those who agreed to participate could move further in the questionnaire. This was accepted as consent for the study. The form was set in such a way that the student can participate only once. Participants were allowed to withdraw from the study without filling the questionnaire if they were willing to do so. Participants' confidentiality was maintained by using code number for each participant and not revealing their individual identity in the report findings. The first reminder email was sent on the 3rdth day and the second on 5th day.

After collection of data, data were checked out thoroughly then edited, coded and transferred into SPSS 16. The data were analyzed and calculated according to the nature of data in terms of descriptive statistics and inferential statistic. Descriptive statistic was used for demographic characteristics. Whereas ANOVA test was used to see the mean difference between different years of PCL $\left(1^{\text {st }}, 2^{\text {nd }}\right.$ and $3^{\text {rd }}$ year $)$, B.Sc. Nursing $\left(1^{\text {st }}, 2^{\text {nd }}\right.$, $3^{\text {rd }}$ and $4^{\text {th }}$ year $)$ and BNS $\left(1^{\text {st }}, 2^{\text {nd }}\right.$ and $3^{\text {rd }}$ year) and independent t- test was used to see the difference in stress between first and final year nursing students.

The study instrument consisted three sections- information sheet and consent; demographic information and Perceived Stress Scale (PSS) ${ }^{[6]}$ for stress, Generalized Anxiety Disorder (GAD-7) ${ }^{[7]}$ for anxiety and Patient Health Questionnaire (PHQ-9) for depression regarding COVID-19.

Stress was measured by Perceived Stress Scale (PSS). ${ }^{[6]}$ It is the most widely used psychological instrument for measuring the perception of stress by Cohen, 1988. It consists of 10 items, divided into subscales with similar content. It uses a five point scale with options of "never", "almost never", "sometimes", "fairly often" and "very often", scored as $0,1,2$, 3and 4 respectively. PSS scores are obtained by reversing responses $(0=4,1=3,2=2,3=$ $1 \& 4=0$ ) to the four positively stated items (items 4, 5, 7, \& 8) and then summing across all scale items. Individual scores on the PSS ranged from 0 to 40 . Scores ranging from 0-13 was considered low stress, 14-26 moderate stress and 27-40 was high perceived stress. The Cronbach's alpha reliability coefficient for thePSS-10 total Score is $0.89^{[5]}$ and for the PHQ-ADS, internal reliability of Cronbach's alpha value is 0.8 to $0.9{ }^{[6]}$

Anxiety was measured by Generalized Anxiety Assessment (GAD-7). [7] GAD-7 includes seven items based on seven core symptoms of anxiety. The questionnaire asks participants how often, during the last 2 weeks, they were bothered by each symptom. Respondents report their symptoms using a 4-item Likert rating scale 
ranging from 0 to 3 . It was calculated by assigning scores of $0,1,2$, and 3 , to the response categories of "not at all," "several days," "more than half the days," and "nearly every day," respectively. Total score ranges from 0 to 21 . Scores represented Anxiety Severity: $<5$ minimal, 5-9 mild, 1014 moderate anxiety and $\geq 15$ severe anxiety. The GAD-7 is a well-validated screening instrument, and it has demonstrated excellent internal consistency (Cronbach's a $=0.92$ ).

Depression was measured by the patient Health Questionnaire (PHQ-9) scale.

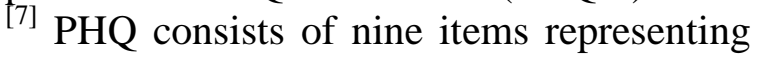
the criterion symptoms for depressive disorder. The questionnaire inquired the frequency with which respondents suffered from these symptoms within last two weeks. It was calculated by assigning scores of 0,1 , 2 , and 3, to the response categories of "not at all," "several days," "more than half the days," and "nearly every day," respectively. Individual scores on the PSS can range from 0 to 27. Scores represent depression severity: 0-4 none, 5-9 mild, 10-14 moderate, 15-19 moderately severe, 20-27 severe. For PHQ internal reliability of Cronbach's alpha value is 0.8 to 0.9 .

\section{RESULTS}

Table 1 showed that $13.6 \%$ nursing students were of age 25-33 years. 39\% of students were studying Bachelor of Science (B.Sc) in Nursing and only 6\% were from masters' level. Most (97.9\%) of students were living with family. More than half of students (57.9\%) were from Bagmati Pradesh and most of them $(87.2 \%)$ were unmarried.

Table 2 revealed that $72.8 \%$ nursing students had moderate level and $2.9 \%$ had high perceived stress, $52.9 \%$ had mild anxiety and only $2.1 \%$ had severe anxiety. Regarding depression, $57.6 \%$ did not have depressive symptoms and only $1 \%$ had severe depression.

Table 1: Nursing students' socio-demographic characteristics, n $=382$

\begin{tabular}{|l|l|l|}
\hline Variables & $\begin{array}{l}\text { Frequency } \\
(\mathbf{n})\end{array}$ & $\begin{array}{l}\text { Percentage } \\
(\%)\end{array}$ \\
\hline Age (in years) & & \\
\hline $16-24$ & 321 & 84 \\
\hline $25-33$ & 52 & 13.6 \\
\hline $34-42$ & 9 & 2.4 \\
\hline Educational programme & & \\
\hline $\begin{array}{l}\text { Proficiency certificate level } \\
\text { Nursing (P.C.L) }\end{array}$ & 110 & 28.8 \\
\hline $\begin{array}{l}\text { Bachelor of Science in Nursing } \\
\text { (B.Sc.) }\end{array}$ & 149 & 39 \\
\hline $\begin{array}{l}\text { Bachelor in Nursing Science } \\
\text { (BNS) }\end{array}$ & 100 & 26.2 \\
\hline Masters in Nursing (MN) & 23 & 6.0 \\
\hline Living & & \\
\hline Alone & 8 & 2.1 \\
\hline With family & 374 & 97.9 \\
\hline Province & & \\
\hline Province no. 1 & 23 & 6.0 \\
\hline Province no. 2 & 21 & 5.5 \\
\hline Bagmati Pradesh & 221 & 57.9 \\
\hline Gandaki Pradesh & 88 & 23.0 \\
\hline Province no. 5 & 22 & 5.8 \\
\hline Karnali Pradesh & 5 & 1.3 \\
\hline Sudurpaschim Pradesh & 2 & .5 \\
\hline Marital status & 393 & 12.8 \\
\hline Married & & 87.2 \\
\hline Unmarried & & \\
\hline
\end{tabular}

Table 2: Students' level of stress, anxiety and depression, $n$ $=382$

\begin{tabular}{|l|l|l|}
\hline Items & Frequency (n) & Percent (\%) \\
\hline Level of stress & & \\
\hline Low (0-13) & 93 & 24.3 \\
\hline Moderate (14-26) & 278 & 72.8 \\
\hline High Perceived (27-40) & 11 & 2.9 \\
\hline Level of anxiety & & \\
\hline Minimal $(<5)$ & 202 & 52.9 \\
\hline Mild(5-9) & 121 & 31.7 \\
\hline Moderate $(10-14)$ & 51 & 13.4 \\
\hline Severe $(\geq 15)$ & 8 & 2.1 \\
\hline Level of Depression & & \\
\hline None (<5) & 220 & 57.6 \\
\hline Mild (5-9) & 109 & 28.5 \\
\hline Moderate(10-14) & 36 & 9.4 \\
\hline Moderately severe $(15-19)$ & 13 & 3.4 \\
\hline Severe $(\geq 20)$ & 4 & 1.0 \\
\hline
\end{tabular}

Table 3 reveals that significant mean difference was found in stress, anxiety and depression among PCL, B. Sc and BNS students with $\mathrm{p}$ value less than .05. This showed that PCL students were more likely to be stressed, anxious and depressed than B.Sc and BNS due to COVID 19.

\begin{tabular}{|c|c|c|c|c|c|c|c|c|c|c|c|c|c|}
\hline \multirow[b]{2}{*}{ Program } & \multirow[b]{2}{*}{$\mathrm{N}$} & \multicolumn{4}{|c|}{ Stress during COVID } & \multicolumn{4}{|c|}{ Anxiety during COVID } & \multicolumn{4}{|c|}{ Depression during COVID } \\
\hline & & Mean & SD & $\mathrm{F}$ & P value & Mean & SD & $\mathrm{F}$ & P value & Mean & SD & $\mathrm{F}$ & $\mathrm{P}$ value \\
\hline PCL & 110 & 18.25 & 5.26 & 9.0 & $.00^{*}$ & 5.90 & 4.48 & 9.56 & $.00^{*}$ & 5.97 & 4.63 & 8.68 & $.00^{*}$ \\
\hline B.Sc. & 149 & 17.89 & 5.26 & & & 5.46 & 4.02 & & & 5.04 & 4.51 & & \\
\hline BNS & 100 & 15.42 & 5.36 & & & 3.55 & 3.94 & & & 3.45 & 4.02 & & \\
\hline
\end{tabular}


Table 4 illustrates that comparing the mean difference of stress, anxiety and depression among different years of PCL, BSc and BNS students, significant mean difference was found in depression among PCL nursing students with $\mathrm{p}$ value $<0.05$. PCL $1^{\text {st }}$ year students were more likely to have more depressive symptoms than second and third year.
Among B.Sc. nursing students, fourth year were more likely to have more stressed, anxious and depressed than first, second and third year. Among BNS students, first year are more likely to have more stress, anxiety and depressive symptoms.

Table 4: Mean difference in stress, anxiety and depression among different years of PCL, BSc. and BNS nursing students

\begin{tabular}{|c|c|c|c|c|c|c|c|c|c|c|c|c|c|}
\hline \multirow{2}{*}{ Prog. Year } & \multirow[b]{2}{*}{$\mathbf{N}$} & \multicolumn{4}{|l|}{ Stress } & \multicolumn{4}{|c|}{ Anxiety } & \multicolumn{4}{|c|}{ Depression } \\
\hline & & Mean & SD & $\mathbf{F}$ & $P$ value & Mean & SD & $\mathbf{F}$ & $P$ value & Mean & SD & $\mathbf{F}$ & $P$ value \\
\hline \multicolumn{14}{|l|}{ PCL } \\
\hline $1^{\mathrm{st}}$ & 39 & 17.49 & 6.70 & 2.47 & .08 & 6.59 & 4.84 & 2.73 & .069 & 7.10 & 4.28 & 6.92 & $.00^{*}$ \\
\hline $2^{\text {nd }}$ & 36 & 19.83 & 3.49 & & & 6.56 & 4.39 & & & 6.97 & 5.43 & & \\
\hline $3^{\text {rd }}$ & 35 & 17.49 & 4.71 & & & 4.46 & 3.91 & & & 3.69 & 3.17 & & \\
\hline \multicolumn{14}{|l|}{ B.Sc. } \\
\hline $1^{\mathrm{st}}$ & 37 & 17.86 & 5.49 & .32 & .80 & 5.65 & 4.07 & .45 & .714 & 5.65 & 5.14 & .44 & .71 \\
\hline $2^{\text {nd }}$ & 38 & 17.47 & 4.87 & & & 5.05 & 3.38 & & & 4.79 & 3.07 & & \\
\hline $3^{\text {rd }}$ & 36 & 17.61 & 5.21 & & & 5.14 & 4.27 & & & 4.50 & 4.55 & & \\
\hline $4^{\text {th }}$ & 38 & 18.58 & 5.60 & & & 6.00 & 4.40 & & & 5.21 & 5.07 & & \\
\hline \multicolumn{14}{|l|}{ BNS } \\
\hline $1^{\mathrm{st}}$ & 36 & 16.25 & 6.03 & 1.13 & .32 & 4.22 & 4.30 & 1.18 & .309 & 4.36 & 4.62 & 2.03 & .13 \\
\hline $2^{\text {nd }}$ & 32 & 14.31 & 4.26 & & & 2.75 & 2.87 & & & 2.41 & 2.76 & & \\
\hline $3^{\text {rd }}$ & 32 & 15.59 & 5.52 & & & 3.59 & 4.39 & & & 3.47 & 4.23 & & \\
\hline
\end{tabular}

Table 5 showed that while comparing mean differences of stress, anxiety and depression between first year and final year of PCL, B.Sc and BNS students, significant findings were found among PCL nursing first year and final year students with $\mathrm{p}$ value 0.05 .

Table 5: Mean difference in stress, anxiety and depression between first year and final year PCL, B.Sc. and BNS nursing students

\begin{tabular}{|c|c|c|c|c|c|c|c|c|c|c|c|c|c|}
\hline & \multicolumn{5}{|c|}{ Stress } & \multicolumn{4}{|c|}{ Anxiety } & \multicolumn{4}{|c|}{ Depression } \\
\hline Prog year & $\mathbf{N}$ & Mean & SD & T-test & Sig & Mean & SD & T-test & Sig & Mean & SD & T-test & Sig \\
\hline \multicolumn{14}{|l|}{ PCL } \\
\hline $1^{\mathrm{st}}$ & 39 & 17.49 & 6.70 & $.00^{*}$ & .99 & 6.59 & 4.84 & 2.06 & $.04^{*}$ & 7.10 & 4.28 & 3.85 & $.00^{*}$ \\
\hline Final & 35 & 17.49 & 4.71 & & & 4.46 & 3.91 & & & 3.69 & 3.17 & & \\
\hline \multicolumn{14}{|l|}{ B.Sc } \\
\hline $1^{\mathrm{st}}$ & 37 & 17.86 & 5.49 & -.55 & .57 & 5.65 & 4.07 & -.35 & .72 & 5.65 & 5.14 & .37 & .71 \\
\hline Final & 38 & 18.58 & 5.60 & & & 6.00 & 4.40 & & & 5.21 & 5.07 & & \\
\hline \multicolumn{14}{|l|}{ BNS } \\
\hline $1^{\text {st }}$ & 36 & 16.25 & 6.03 & .46 & .64 & 4.22 & 4.30 & .59 & .55 & 4.36 & 4.62 & .82 & .41 \\
\hline Final & 32 & 15.59 & 5.52 & & & 3.59 & 4.39 & & & 3.47 & 4.23 & & \\
\hline
\end{tabular}

\section{DISCUSSION}

In the current study among 382 nursing, $93(24.3 \%)$ nursing students had low level of stress, $278(72.8 \%)$ had moderate level of stress and $11(2.9 \%)$ had high level of perceived stress. Contradictory findings was seen in study conducted in Chitwan, Nepal where low stress was found in $8.7 \%$ nursing students, moderate in $84.1 \%$ and high perceived stress in $7.2 \%$. ${ }^{[5]}$ In India, $37.7 \%$ had no stress, $24.7 \%$ had slight stress, $27.9 \%$ had moderate stress,
$6.9 \%$ had high stress $2.8 \%$ had extreme stress. ${ }^{[8]}$ Similarly in turkey, $36.3 \%$ were normal, $29.7 \%$ had mild stress, $22.1 \%$ had moderate, $10 \%$ had severe and $1.9 \%$ had very severe stress. ${ }^{[9]}$ In Southern California, USA, almost a quarter $(24.7 \%)$ of nursing students reported high stress ${ }^{[14]}$ which is contradictory to this research finding.

Regarding anxiety, this survey indicated that $202(52.9 \%)$ students experienced minimal anxiety, 121(31.7\%) had mild anxiety, 51(13.4\%) experienced 
moderate anxiety and only $8 \quad(2.1 \%)$ experienced severe anxiety during COVID 19 pandemic. In accordance to this finding, in turkey $49.1 \%$ were normal, $17.8 \%$ had mild, $16.5 \%$ had moderate, $7.1 \%$ had severe and $9.5 \%$ had very severe anxiety. ${ }^{[9]}$ In Southern California, USA, more than half $(55.2 \%)$ nursing students reported moderate-to-severe symptoms of anxiety. [14]

Contrary to our results, a similar study reported that $21.3 \%, 2.7 \%$ and $0.9 \%$ of Chinese college students had mild, moderate and severe anxiety, respectively. [10]. Similarly, study conducted among students in Nepal revealed that $25.7 \%$ had mild, $22.9 \%$ had moderate and $18.1 \%$ had severe anxiety ${ }^{[11]}$ where as in contrast, a study conducted in Bangladesh showed $18.3 \%, 38.9 \%, 24.8 \%$ and $18.1 \%$ students had minimal, mild, moderate and severe anxiety respectively. ${ }^{[12]}$ Study conducted in Chitwan revealed that $45.4 \%$ had mild anxiety, $33.3 \%$ had moderate anxiety, and $21.3 \%$ had severe anxiety. [5] Anxiety among nursing students in the Ashkelon Academic College, Southern District, Israel revealed that $42.8 \%$ had moderate and $13.1 \%$ had severe anxiety. ${ }^{[13]}$

In current study, more than half $(57 \%)$ of students didn't have depressive symptoms. $28.5 \%$ were having mild depression, $9.4 \%$ had moderate depression, $3.4 \%$ had moderately severe and only $1 \%$ had severe depression. In contrast to this findings study done in Pakistan showed that $30.5 \%, 24.5 \%, 21 \%, 13.6 \%$ and $10.4 \%$ had none, mild, moderate, moderately severe and severe symptoms respectively. [4] Similarly contradictory findings were seen in Bangladesh where $17.6 \%$ had nonminimal, $28.6 \%$ had mild, $27.9 \%$ had moderate, $15.1 \%$ had moderately severe and $10.7 \%$ had severe symptoms. ${ }^{[12]}$ In addition to this, study conducted in turkey showed that $44.5 \%$ were normal, $9.7 \%$ had mild, $21.7 \%$ had moderate, $13.1 \%$ had severe and $10.9 \%$ had severe depression ${ }^{[9]}$ in contrast to this findings, in Southern California, USA, more than half $(51.5 \%)$ nursing students reported moderate-tosevere symptoms of depression. ${ }^{[14]}$

In this study, significant mean difference was found in stress, anxiety and depression among PCL, B. Sc and BNS students with $\mathrm{p}$ value less than .01. This showed that PCL students were more likely to be stressed, anxious and depressed than B.Sc and BNS due to COVID 19. In contrast to this, study conducted in Manmohan Memorial Institute of Health Sciences (MMIHS), Kathmandu Nepal showed that the perceived stress was found to be more in the B.Sc. Nursing students than PCL nursing and BNS. ${ }^{[15]}$ This might be due to younger age and basic level of nursing of PCL students.

While comparing the mean difference of stress, anxiety and depression among different years of PCL, BSc and BNS students, significant mean difference was found in depression among PCL nursing students. PCL $1^{\text {st }}$ year students were more likely to have more depressive symptoms than second and third year. Similar to this findings, $66 \%$ of PCL first year and $68 \%$ of PCL second year students were highly stressed in comparison to third year $(6 \%)$. ${ }^{[16]}$

Among B.Sc. nursing students, fourth year were more likely to have more stressed, anxious and depressed than first, second and third year. This might be as they are in their final year and not being sure of completion of their course on time and their job insecurities. Among BNS students, first year are more likely to have more stress, anxiety and depressive symptoms.

\section{CONCLUSION}

Nearly two third of nursing students had moderate level of stress, one third had low level and very few had high perceived stress during COVID 19. Regarding anxiety, majority had mild anxiety and very few had severe anxiety. More than half did not have depression, more than one third had mild depression and minimal percent had severe depression. Moreover, significant mean difference in stress, anxiety and depression 
between PCL, BSc and BNS level were found to be highly significant with $p$ value less than 0.05. This showed that PCL students were more likely to be stressed, anxious and depressed than B.Sc. and BNS due to COVID 19.

\section{Funding Source}

This research did not receive any specific grant from funding agencies in the public, commercial, or not-for-profit sectors.

\section{ACKNOWLEDGEMENT}

The author is grateful to the Patan Academy of Health Sciences School of Nursing and midwifery and all the nursing students who participated in the study.

\section{Conflict of Interest}

The author has no conflict to interest to declare.

\section{Ethical Approval: Approved}

\section{REFERENCES}

1. World Health Organization. Coronavirus disease (COVID-19) pandemic. 2020. Acessadoem. 2020. Retrieved from: https://www.who.int/emergencies/diseases /novel-coronavirus-2019

2. Islam MS, Sujan MS, Tasnim R, Sikder MT, Potenza MN, Van Os J. Psychological responses during the COVID-19 outbreak among university students in Bangladesh. DOI:10.31234/osf.io/cndz7. Retrieved from

3. https://www.researchgate.net/publication/ 341829205

4. Odriozola-Gonzalez P, Planchuelo-Gomez A, Irurtia MJ, de Luis-Garcia R. Psychological effects of the COVID-19 outbreak and lockdown among students and workers of a Spanish university. Psychiatry Research. 2020 May 19:113108.

5. Salman M, Asif N, Mustafa ZU, Khan TM, Shehzadi N, Hussain K, Tahir H, Raza MH, Khan MT. Psychological impact of COVID-19 on Pakistani university students and how they are coping. Medrxiv. 2020 Jan 1.

6. Subba R, Subba HK, Singh JP, Mehta RK. Psychological Impact and Coping Strategies of Nursing Students during the Outbreak of Coronavirus Disease in Nepal. Asian Journal of Multidisciplinary Studies. 2020 Sep;8:9.

7. Cohen S, Kamarck T, Mermelstein R. A global measure of perceived stress. J Health Soc Behavior. 1983;24(4):385-96.

8. Kroenke K, Wu J, Yu Z, Bair MJ, Kean J, Stump T, Monahan PO. The patient health questionnaire anxiety and depression scale (PHQ-ADS): Initial validation in three clinical trials. Psychosomatic medicine. 2016 Jul;78(6):716.

9. Ramyarathidevi M, Mathiazhakan $U$, Tamilselvi S, Priya V, Arifa Bee S, Kanniammal C , Assessment of level of academic stress and stress coping style on impact of lockdown COVID 19 among nursing students at SRM college of Nursing, Chengalpattu (dt) Int. J. Res. Pharm. Sci., 2020, 11 (SPL)(1), 1156-116

10. Kalkan Ugurlu Y, Mataracı Degirmenci $D$, Durgun $H$, Gok Ugur H. The examination of the relationship between nursing students' depression, anxiety and stress levels and restrictive, emotional, and external eating behaviors in COVID19 social isolation process. Perspectives in Psychiatric Care. 2020 Dec 3.

11. Cao W, Fang Z, Hou G, Han M, Xu X, Dong J, Zheng J. The psychological impact of the COVID-19 epidemic on college students in China. Psychiatry research. 2020 May 1;287:112934.

12. Dangal MR, Bajracharya LS. Students Anxiety Experiences during COVID-19 in Nepal. Kathmandu University Medical Journal. 2020 Nov 19;18(2):53-7.

13. Islam MA, Barna SD, Raihan H, Khan MN, Hossain MT. Depression and anxiety among university students during the COVID-19 pandemic in Bangladesh: A web-based cross-sectional survey. PloS one. 2020 Aug 26;15(8):e0238162.

14. Savitsky B, Findling Y, Ereli A, Hendel T. Anxiety and coping strategies among nursing students during the covid-19 
pandemic. Nurse Education in Practice. 2020 Jul 1;46:102809.

15. Kim SC, Sloan C, Montejano A, Quiban C. Impacts of Coping Mechanisms on Nursing Students' Mental Health during COVID-19 Lockdown: A Cross-Sectional Survey. Nursing Reports. 2021 Mar; 11(1):36-44.

16. Bista B, Bhattrai B, Khadka N. Stress and coping mechanisms among nursing students in Kathmandu. Journal of
Manmohan Memorial Institute of Health Sciences. 2017;3(1):16-23.

17. Lamichhane K. Factors Associated with Stress among Nursing Students in Pokhara. Hindu.; 92:84.

How to cite this article: Shrestha N, Ghimire $\mathrm{N}$, Khatry $\mathrm{R}$ et.al. Psychological effect of COVID-19 among nursing students. Int $J$ Health Sci Res. 2021; 11(5): 248-254. DOI: https://doi.org/10.52403/ijhsr.20210540 